of Inquiry on the Training of Supervisors and relate these conclusions to their own experience in industry.

The group was in general agreement on three points. First, that the responsibility for training supervisors is one for senior management; second, that industrial training is ineffective if it is of a purely academic character; and third, it is no good giving the supervisor training if his status is not right in the firm. He must be regarded as a member of the management team. The booklet has been prepared in collaboration with the Central Office of Information and with the aid of a grant made available under the Conditional Aid Scheme for the Use of Counterpart Funds derived from United States economic aid. It is not for sale; but copies can be obtained on request from the Director of Public Relations, Ministry of Labour and National Service, 8 St. James's Square, London, S.W.1. The other booklets in the series deal with joint consultation in industry, the spreading of information in the factory and personnel selection.

\section{Scientific Research at South African Universities during 1955}

THE fourth volume of the "Register of Current Scientific Research at South African Universities" covers research conducted during 1955 (pp. 341. Pretoria: Council for Scientific and Industrial Research). The investigations described are arranged under the name of the university department concerned, which is listed alphabetically according to its English name, with occasional subject cross-references. The actual information is given in the language in which it was received from the universities; but headings and sub-headings are in English only, and this year an English translation of the subject of research submitted in Afrikaans is included. Agricultural chemistry and agricultural engineering are indexed as sub-sections of agriculture, and all chemistry entries are entered under the one general heading of chemistry (inorganic, organic and physical). Academic degrees and full professional qualifications are given where these are ascertainable. The volume contains 545 entries.

\section{Royal Scottish Museum, Edinburgh : Report for 1955}

THE annual report for 1955 of the Royal Scottish Museum, Edinburgh (pp. 16; from the Museum; 1956), is a record of steady progress, especially in the related work carried out for cultural and educational institutions. Following the example of the director, Dr. D. A. Allan, who has contacts both at national and international levels, members of the senior staff have made many personal contributions to a wide variety of educational and cultural organizations in the field of museum work. It is unfortunate that the long-needed lecture hall is still in the drawing-board stage.

Government Museum, Madras : Report for 1954-55

THE annual report of the Government Museum, Madras, for $1954-55$ (pp. $46+2$ plates. Madras: Government Press, 1956) records the excellent educational work which is being undertaken by this progressive institution. Certain students in the University of Baroda have been given detailed instructions in museum methods, while other students of the University of Madras were provided with practical demonstrations in anthropology. Despite a limited staff, much preservation work has been carried out, especially in the chemical conservation section where experiments were made concerning the electrolytic method for cleaning coins.

\section{French Metallurgical Society}

THE French Metallurgical Society will hold its autumn meeting in Paris at the Maison de la Chimie during October 22-27. At the meeting the following awards will be presented: the Grand Medal of the Society, to Prof. R. F. Mehl for his work, in general, on metallurgy; the Sainte-Claire-Deville Medal, to R. Gadeau for his work on aluminium of high purity ; and Rist Prizes, to F. Montariol and J.-P. Moreau. A special feature of the meeting will be a series of papers on non-destructive methods for the study and control of metals. Further information can be obtained from the Société Française de Métallurgie, 25 rue de Clichy, Paris 9 e.

\section{"Prophylaxis of Trypanosome Infections in Cattle"}

Messrs. T. I. Watkins and G. Woolfe state that, in their communication under this title published in Nature of August 18, p. 368, they gave an incorrect structure for compound II. The correct structure is

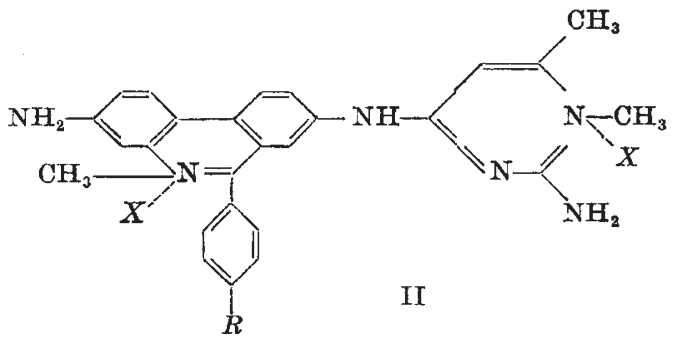

\section{Announcements}

Mr. R. E. GLover, principal and dean of the Royal Veterinary College, has been appointed a member of the Agricultural Research Council in succession to Prof. G. R. Cameron, who has resigned; Prof. S. J. Watson has been appointed for a further term as a member of the Council and will continue as deputy chairman.

THE fifth annual convention of the Scientific Instrument Manufacturers' Association will be held in Eastbourne during October 11-14, under the general theme of "Production 1957". There will be four panels on the following topics : general, optical and mechanical production; electrical and electronic production; research and development ; and marketing. The guest speaker on the opening day will be Mr. Stanley J. Harley, of the Coventry Gauge and Tool Co., Ltd. Further information can be obtained from the Association at 20 Queen Anne Street, London, W.1.

A conference on "Gas 'Iurbine Development", arranged by the Department of Engineering of the North Herts Technical College, Broadway, Letchworth, will be held in the College during October 20-21. There will be four papers, covering the development of the gas turbine in the following respective fields : industry; motor vehicles; ships; and aircraft. Further information can be obtained from the North Herts Technical College. 